\title{
Full-Length Genomic Characterization of Chicken Anemia Virus in Turkey
}

http://dx.doi.org/10.1590/1806-9061-2018-0937

Original Article

\section{mAuthor(s)}

Aşkar S' (iD) https://orcid.org/0000-0002-7836-3798

Çankırı Karatekin University, Faculty of Health Science, Department of Nutrition and Dietetics, 18200, Çankırı/Turkey.

\section{-Mail Address}

Corresponding author e-mail address Şinasi Așkar

Çankırı Karatekin University, Faculty of Health Science, Department of Nutrition and Dietetics, Çankırı 18200, Turkey. Phone: 0-543-5703485

Email: sinasia@gmail.com

\section{ABSTRACT}

Chicken infectious anemia (CIA) is an immune-suppressive disease caused by chicken anemia virus (CAV). It is characterized by lymphoid atrophy, aplastic anemia, especially in chicks. In this study, full-length genomic characterization of CAV DNA from the broiler flocks in Turkey and phylogenetic analysis were aimed.

In the study, CAV DNA were found positive for 37 (53\%) flocks with PCR studies from thymus tissues of each 70 broiler flocks. And 17 purified CAV DNA PCR products from these 37 CAV isolates were full length sequenced with the NGS method (Illumina MiSeq).

Also with the phylogenetic analyses, full length PCR products of 17 purified CAV isolates have been determined as 2298bp genome size and $99 \%$ similarity with each other. The highest similarity (99\%) has been detected with the isolates from China and Taiwan. Furthermore, a 97-98\% similarity has been detected with vaccine strains (Cux-1, 26P4 and Del Ros) and also 88-90 \% similarity has been detected with GyV4 and GyV3 isolates.

As a result, in the study full length genomic characterization of CAV DNA from the 7 regions of Turkey were determined. And also all Turkish CAV isolates and vaccine strains were in group 2 according to the phylogenetic tree were obtained. But these isolates and vaccine strains were not found in the same group with GyV3 and GyV4 strains. Besides, these CAV isolates were showed more similarity to the isolates reported from Taiwan and China than the vaccine strains.

\section{INTRODUCTION}

Chicken infectious anemia $(\mathrm{CIA})$ is an immune suppressive disease caused by CAV. Disease is characterized by aplastic anemia and generalized lymphoid atrophy in young chickens. CIA disease can cause significant economic losses in the poultry industry due to immunosuppression, subclinical, horizontal and vertical spread, resistance to disinfection, and lack of protective vaccination against CIA infection in commercial broilers (Schat, 2003).

Vaccination strategies are based on the preventing of vertical transmission of virus by immunization of breeder flocks and the passage of adequate maternal antibody to the young chicks (Schat, 2003). However, Aşkar \& Yıldırım (2011) reported protective maternal antibody titer decreased from 2 weeks of age and CAV positivity was increased in commercial chicken flocks from 3 weeks of age. Three different commercial live vaccines (Cux-1, 26P4, Del Ros strains) have been used in Turkey.

Chicken anemia virus (CAV, Gifu -1 strain) was first isolated by Yuasa et al., in 1979. CAV has been classified in the Gyrovirus genus of the Anelloviridae (Rosario et al., 2017; ICTV 2018). CAV consists of 2298 
or 2319 bp single stranded ambisense or negative sense DNA genome. The viral genome contains three complete major open reading frames (ORF) that encode for 3 viral proteins; VP1, VP2, and VP3 (Noteborn et al., 1991). VP1 is the major viral structural protein which is associated with viral replication, cell infection ability and virulence. Although the amino acid (aa) composition of CAV is very conservative, VP1 displays significant variability in certain regions (e.g., amino acid positions 139-151). If both of the amino acids in position 139. and 144. are glutamines, virulence and replication ability of the virus is relatively weaker (Farkas, 1996; Renshaw et al., 1996; Yamaguchi et al., 2001; Schat, 2003).

Previous epidemiological studies on the molecular and serological determination of CAV infection in Turkey and the other countries (Hadimli et al., 2008; Aşkar \& Yıldırım, 2011). In recent years, sequence differences in the CAV genome and genome similarities with Gyrovirus of other organisms, especially human beings, have been examined (Krapez et al., 2006; Hailemariam et al., 2008; Kim et al., 2010; Abo Elkhair et al., 2014, Li et al., 2017). In 2011, a new human virus called 'Human Gyrovirus' (HGyV) which shows homology with CAV was isolated from the human skin surface (Sauvage et al., 2011). In China, two Gyrovirus species were identified in 2012, and they are named as GyV3 and GyV4. These viruses were found in fecal samples of human consuming CAV infected and/or vaccinated chickens (Phan et al., 2012; Zhang et al., 2012). In addition, it was reported that CAV genome showed many similarities with these viruses that caused infection in humans (Chu et al., 2012; Maggi et al., 2012). This data suggests that, after consumption of chicken infected with CAV or injected with CAV, CAV has the potential to threaten human health (Zhang et al., 2013).

In this study, full-length genomic characterization of CAV from the broiler flocks of in Turkey and phylogenetic analysis were aimed. Furthermore, the sequences of representative 132 full length CAV isolates in CAV vaccine, human GyV3 and GyV4 including GenBank by phylogenetic methods were compared.

\section{MATERIAL AND METHODS}

\section{Clinical Samples and DNA isolation}

Thymus samples $(n=700)$ were collected from 70 commercial broiler chicken flocks (aged 5-6 week and didn't show any clinical signs) after slaughter in the 7 different regions of Turkey during 2015-
2016. Thymus tissues $(n=10)$ from each flock were mixed and homogenized. Therefore, 70 tissue pools were obtained. Total DNA was isolated from the supernatant of the 70 tissue pool homogenates by using a commercial QIAamp MinElute Virus Spin Kit (Qiagen Science- Cat No.: 57704) according to the manufacturer's instructions. All samples were stored at $-80^{\circ} \mathrm{C}$.

\section{Detection and Amplification of CAV Genome}

PCR analyses were performed for the determination of CAV DNA and obtaining the full length genome from tissues. During PCR amplification, primer pairs of CQ1F 5'-CAATCACTCTATCGCTGTGT-3', CQ1R 5'-TTCGTCCATCTTGACTTTCT-3' and CQ2F 5'-GGCTACTATTCCATCACCATTCT-3', CQ2R 5'-GCTCGTCTTGCCATCTTACA-3' were used to amplify 1778-bp and 831-bp size fragments, respectively, covering the entire nucleotide sequence (Zhang et al., 2013). PCR were performed in a $50 \mu \mathrm{L}$ reaction volume containing $1 \mu \mathrm{L}$ forward primer, $1 \mu \mathrm{L}$ reverse primer, $1,5 \mu \mathrm{L}$ DNA, 1,5 $\mu \mathrm{L}$ dNTPs $(10 \mathrm{mM})$, $12.5 \mu \mathrm{L}$ 10x Platinum Pfx Taq DNA polymerase buffer, $0.5 \mu \mathrm{L}$ Platinum Pfx Taq DNA Polymerase (Thermo Fischer Scientific Cat. No. 11708039) and $32 \mu \mathrm{L}$ ultrapure distilled water. PCR cycle conditions were $94^{\circ} \mathrm{C}$ for $3 \mathrm{~min}$ for pre-denaturation, followed by 30 cycles of $94^{\circ} \mathrm{C}$ for $60 \mathrm{~s}, 57^{\circ} \mathrm{C}$ for $60 \mathrm{~s}$, and $68^{\circ} \mathrm{C}$ for $180 \mathrm{~s}$; a final extension step was set at $72^{\circ} \mathrm{C}$ for 7 min prior to termination of the reaction at $4{ }^{\circ} \mathrm{C}$.

All PCR for each sample were performed in duplicate. The PCR products were analyzed in $1 \%$ agarose gels stained with ethidium bromide.

\section{Sequencing, Alignment and Phylogenetic Analysis of Full-length CAV Genome}

DNA libraries were obtained 17 CAV isolates PCR products of purified using Nextera XT DNA Library Preparation Kit (Illumina, Cat No. FC-131-1096). Then, adapters containing the index arrays (P5\&P7 probes and Illumina-compliant sequence primers) were added to fragments tagged with amplification process. Samples were purified (AmpureXP bead, Beckman Coulter kit) and quantity determination was made (Qubit dsDNA HS Assay Kit). In 4 nM concentration obtained, concentration was reduced 20 pM by applying MiSeq denaturation process from DNA libraries. From the obtained library, $600 \mu \mathrm{l}$ amount was taken and loaded to MiSeq cartridge, and cartridge was placed in device, new generation sequence (NGS) was performed. 
Galaxy software was used to filter read errors of the device and remove erroneous readings from FASTQ data obtained by NGS (Illumina MiSeq). Genomic data was obtained from readings with quality control completed after pre-processing without using reference genome (Denova method). Thus, full length genome belonging to our sample was mapped by combining small reading pieces. These steps were repeated for all examples. Galaxy Web portal (https://usegalaxy.org/) was used during the mapping of array data.

The obtained 17 full length genome data were compared with $132 \mathrm{CAV}$ full-length genome which are including vaccine strains, GyV3 and GyV4 reference genomes previously reported by deposited in GenBank. To compare multi-genome sequence alignment studies and VP1 protein amino acid sequences, Clustal Omega (Multiple Sequence Alignment) was used to apply multiple alignments among them. In phylogenic tree formation, Phylogeny and PHYLIP packaged software were used. Obtained phylogenetic analysis data were tested in "in-silico", and verification of study was performed.

\section{RESULTS}

\section{Detection and Amplification of CAV Genome}

According to PCR results conducted using two different primer pairs, CAV DNA presence was detected from 37 of 70 commercial broiler flocks. In tissue samples with non-determined CAV, it was confirmed whether a DNA inhibitor existed using internal control. Thus, the PCR results were verified. After PCR analyses, 17 PCR products were sequenced and the PCR gel images were given in Figure 1.

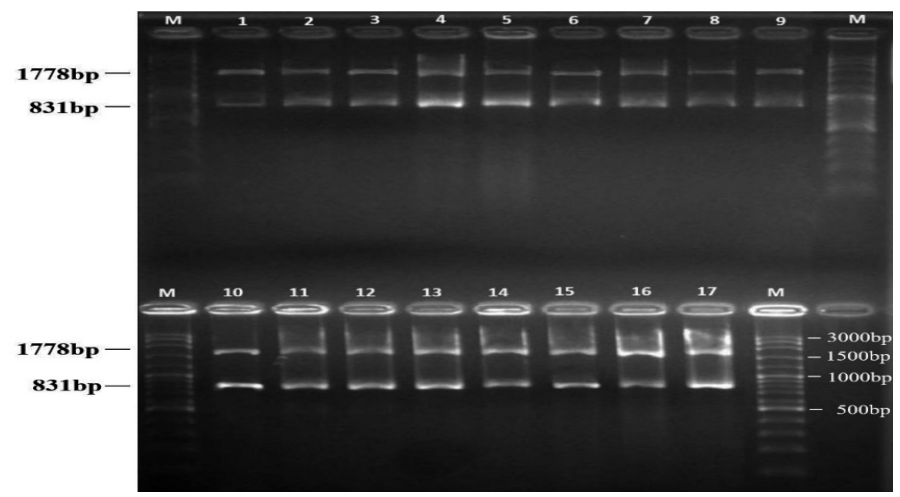

Figure 1 - Electrophoresis of PCR products of 17-purified CAV DNA isolates.

\section{Sequencing, Alignment and Phylogenetic Analysis of Full-length CAV Genome}

PCR products were sequenced after measurement of concentration values (in range of $10-81 \mathrm{ng} / \mathrm{\mu l}$ ) by
Qubit. After sequencing obtained FASTQ data were applied to array analysis, and thus the whole genome sequence was determined. In the study, it was determined that all isolates were in 2298bp genome size.

Phylogenetic distance matrices of 17 purified CAV isolates from Turkey, 132 CAV strains and 2 HGyV fulllength genome sequences were analyzed. Obtained affinity relations are given by Phylogenetic tree in Figure 2.

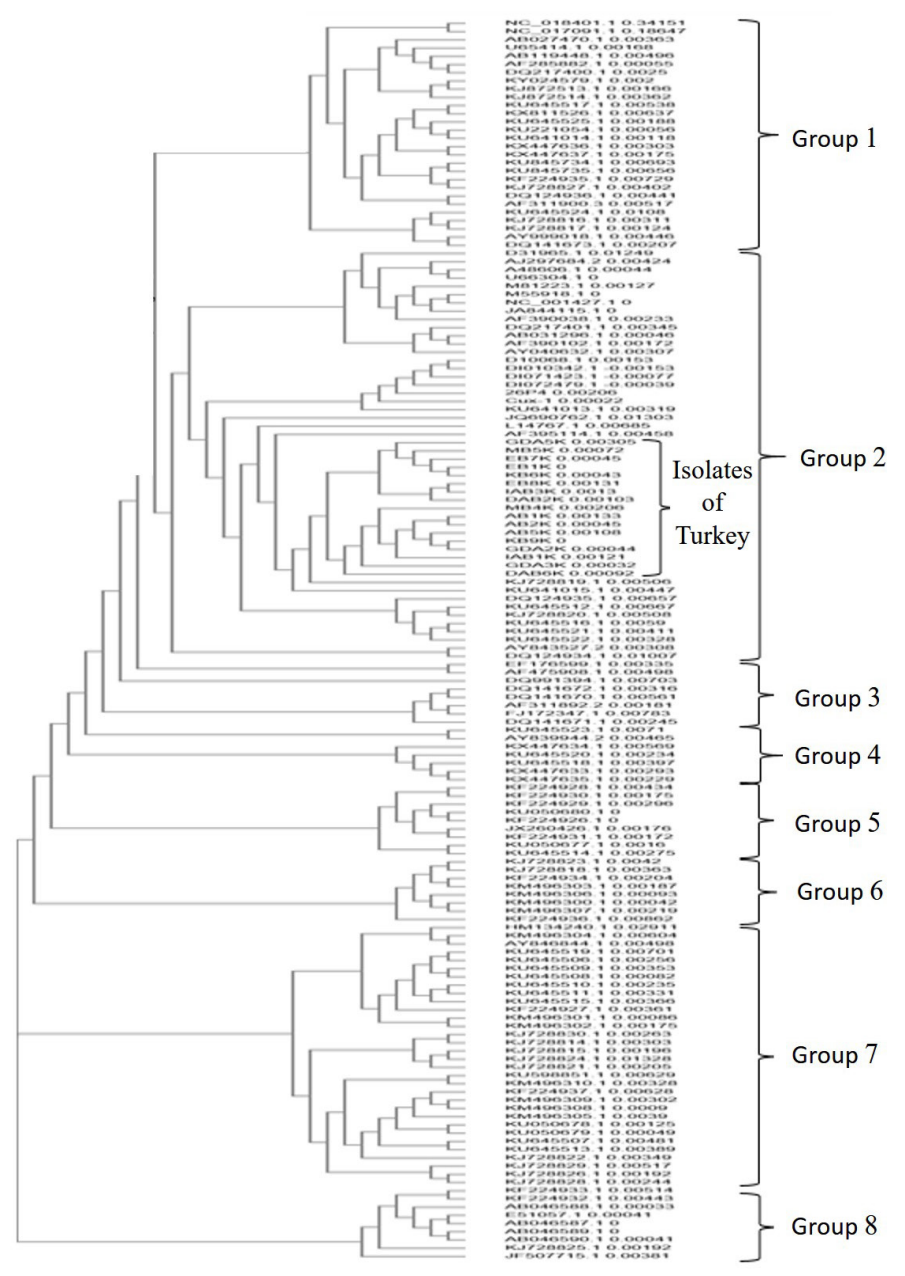

Figure 2 - Full-length genome sequences phylogenetic tree of 17 purified CAV genome in turkey, 132 CAV and 2 Human Gyrovirus genome in GenBank using Neighbour joining method that used clustal tree format, distance correction on, exclude gaps off parameters. Phylogenetic tree files were obtained from shuffle the sequence data matrix five times.

Eight groups were detected according to the phylogenetic tree obtained from the genome sequence of 151 isolates. All field isolates, reference genome and vaccine strains were found in the 2 nd group of phylogeny. According to the data obtained from the phylogenetic tree, the highest similarity of Turkey CAV isolates were determined with China (Access no: KU641015, DQ124935, KU641016, KU645521, KU645522) and Taiwan isolates (KJ728819, KJ728820) 
in $99 \%$ percentage. Also, high similarity with a $97 \%$ percentage was determined with vaccine strains (Cux1, 26P4 and Del Ros).

When the Turkey's CAV genome data were compared with Human Gyrovirus genome data in GenBank, full length genome nucleotide similarities were found with GyV3 and GyV4 between 88-90\% percentages.
VP1 protein amino acid sequences of reference genome, vaccine strains and 17 purified CAV isolates were compared with the Clustel Omega (Multiple Sequence Alignment). According to the obtained data (given in Table 1), CAV's (from field) VP1 proteins amino acid sequences showed similarities among each other, but there were differences with reference genome and vaccine strains.

Table 1 - Differences of VP1 protein aminoacid sequences among, vaccine and Turkey CAV isolates.

\begin{tabular}{|c|c|c|c|c|c|c|c|c|c|c|c|c|c|c|c|c|}
\hline & CAV Isolates & & & & & & & o acid & ubstitu & ion in & 1 prot & & & & & \\
\hline & Consensus Positions & 14. & 22. & 75. & 92. & 97. & 139. & 144. & 157. & 251. & 254. & 287. & 290. & 324. & 370. & 446 \\
\hline & $\begin{array}{l}\text { Reference genome } \\
\text { Cux-1 (M55918) }\end{array}$ & $S$ & $\mathrm{H}$ & V & G & $\mathrm{M}$ & K & D & V & Q & G & A & A & $S$ & $S$ & G \\
\hline 1. & TR 1 & & $N$ & 1 & & $\mathrm{~L}$ & Q & $\mathrm{Q}$ & . & $R$ & $E$ & . & $P$ & . & $T$ & \\
\hline 2. & TR 2 & $A$ & $N$ & I & . & $\mathrm{L}$ & Q & Q & . & $R$ & $\mathrm{E}$ & . & $P$ & . & $\mathrm{T}$ & \\
\hline 3. & TR 3 & A & $N$ & 1 & & L & Q & Q & . & $\mathrm{R}$ & $E$ & . & . & . & T & \\
\hline 4. & TR 4 & $A$ & $\mathrm{~N}$ & I & & $\mathrm{L}$ & Q & $\mathrm{Q}$ & . & $\mathrm{R}$ & $E$ & & . & & & \\
\hline 5. & TR 5 & $A$ & $N$ & I & . & L & Q & Q & . & $\mathrm{R}$ & E & . & . & . & $\mathrm{T}$ & \\
\hline 6. & TR 6 & $A$ & $\mathrm{~N}$ & I & . & L & Q & Q & . & $R$ & E & . & . & . & . & . \\
\hline 7. & TR 7 & $A$ & $N$ & 1 & 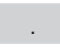 & $\mathrm{L}$ & Q & Q & . & $\mathrm{R}$ & $\mathrm{E}$ & . & . & . & . & \\
\hline 8. & TR 8 & $A$ & $N$ & 1 & . & $\mathrm{L}$ & Q & $\mathrm{Q}$ & . & $\mathrm{R}$ & $\mathrm{E}$ & . & $P$ & . & . & \\
\hline 9. & TR 9 & $A$ & $N$ & 1 & . & $\mathrm{L}$ & Q & $\mathrm{Q}$ & . & $\mathrm{R}$ & $\mathrm{E}$ & . & . & . & $T$ & \\
\hline 10. & TR 10 & $A$ & $N$ & 1 & . & $\mathrm{L}$ & Q & $\mathrm{Q}$ & . & $\mathrm{R}$ & $\mathrm{E}$ & . & . & . & $T$ & \\
\hline 11. & TR 11 & $A$ & $N$ & 1 & & $\mathrm{~L}$ & Q & Q & . & $\mathrm{R}$ & $\mathrm{E}$ & . & . & . & $T$ & \\
\hline 12. & TR 12 & $A$ & $N$ & I & . & $\mathrm{L}$ & Q & Q & . & $\mathrm{R}$ & E & . & . & . & $\mathrm{T}$ & \\
\hline 13. & TR 13 & A & $N$ & 1 & & $\mathrm{~L}$ & Q & Q & . & $R$ & $\mathrm{E}$ & . & P & P & . & \\
\hline 14. & TR 14 & $A$ & $\mathrm{~N}$ & 1 & & $\mathrm{~L}$ & $\mathrm{Q}$ & $\mathrm{Q}$ & . & $\mathrm{R}$ & E & . & . & . & . & \\
\hline 15. & TR 15 & $A$ & $N$ & 1 & . & $\mathrm{L}$ & Q & $\mathrm{Q}$ & . & $R$ & $\mathrm{E}$ & . & . & . & . & \\
\hline 16. & TR 16 & $A$ & $N$ & 1 & . & $\mathrm{L}$ & $\mathrm{Q}$ & $\mathrm{Q}$ & . & $\mathrm{R}$ & $\mathrm{E}$ & . & . & . & $\mathrm{T}$ & 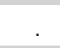 \\
\hline 17. & TR 17 & $A$ & $N$ & 1 & & $\mathrm{~L}$ & $Q$ & $\mathrm{Q}$ & . & $\mathrm{R}$ & $\mathrm{E}$ & . & . & . & . & \\
\hline 19. & 26P4 (AJ890284) & $A$ & . & & $\mathrm{D}$ & . & & E & $M$ & $\mathrm{R}$ & & $\mathrm{T}$ & & & . & $S$ \\
\hline 20. & Del Ros(AF313470) & A & & - & . & . & . & $\mathrm{E}$ & . & $\mathrm{R}$ & $E$ & $\mathrm{~s}$ & . & . & G & \\
\hline
\end{tabular}

A: Alanin, G: Glisin, L: Leucine, P: Prolin, T: Treonin, H: Histidine, I: Isoleucine, M: Methionine, S: Serin, V: Valin, R: Arginin, D: Aspartat, E: Glutamate, Q: Glutamine.

\section{DISCUSSION AND CONCLUSIONS}

In this study, presence of chicken anemia virus (CAV) DNA was investigated in flocks of commercial broilers from 7 different regions of Turkey. This study is the first to demonstrate the CAV genome sequence in Turkey by new generation sequencing (NGS-Illumina) method. According to the data obtained from the study, these genomes sequence similarity were analyzed with commercial vaccine strains (26P4, Cux-1 ve Del Ros) and GyV3, GyV4 viruses which are thought to be related with CAV and has been identified as infection agent in humans. So, important data were obtained about the spread of vaccine strains in field.

When the sequence and phylogenetic results were analyzed, obtained isolates from the field were determined in 2298 bp genome length and have more similarity with the China and Taiwan CAV isolates than the commercial vaccine isolates. This situation suggests that obtained isolates did not directly relate with the vaccine strains (Cuxhaven-1, 26P4 and DelRos) used in Turkey. Comparing amino acid sequences of VP1 protein, which is reported to exhibit variability, it was observed that field isolates have a high rate of similarity at $99 \%$, and have different sequences from vaccine strains.

It was reported that the amino acid in the 394. position of VP1 protein has a major genetic determinant of virulence (Yamaguchi et al., 2001). Ganar et al. (2017) determined glutamine aa. in the 394. position of VP1 protein of all 11 CAV field isolates obtained from India. Similar to results of Ganar et al., glutamine aa. was determined in the 394. position of all 17 isolates isolated from Turkey in this study. This data suggests that all obtained isolates may be pathogenic. In a very variable region, it was reported that 139. and 144. positions had significant role in viral replication and spread in cell culture (Renshaw et al., 1996). Li et al. (2017), were reported in their study that in 24 field isolates glutamine aa. were determined in 
394 position whereas it were determined in the 139. and 144. positions in the 16 isolates. In this study, also the glutamine aa. in 139. and 144. positions in all 17 isolates were determined. This data showed that obtained isolates in this study may have a low viral replication and spread in cell culture.

When the similarities of our CAV isolates from Turkey were compared with human pathogenic GyV3 and GyV4 viruses which shows high similarity to CAV' strain in recent years (Chu et al., 2012; Maggi et al., 2012; Zhang et al., 2012) and other CAV isolates in Gen Bank, low similarity (88-90 \%) has been determined with other CAV isolates.

As a result of this study, CAV were determined from the 7 regions of Turkey and all determined CAV isolates have 2298bp genome size. According to the phylogenetic tree all Turkish CAV isolates and vaccine strains were in group 2 (Table 1) but these were not in the same group with Gyv3 and GyV4 (group 1) isolates. Besides, these CAV isolates were showed more similarity to isolates reported from Taiwan and China, than the vaccine strains. In addition, there is a need for further studies on the presence of Gyv3 and GyV4 in humans and phylogenetic analysis in Turkey.

\section{ACKNOWLEDGEMENTS}

This research was supported by the Turkish Scientific and Technological Research Council (TUBITAK) with Project no: 2150047. Thanks to project supervisor, Prof. Dr. Barış SAREYYÜPOĞLU and GENZ Biotechnology Inc. (Turkey) for their support in phylogenetic studies.

\section{ETHICS STATEMENT}

This study was approved by the Animal Welfare Committee of Kırıkkale University (R.N.:15/01).

\section{REFERENCES}

Abo Elkhair M, Abd El-Razak AG, Metwally A E. Molecular characterization of chicken anemia virus circulating in chicken flocks in Egypt. Advances in Virology 2014; Article ID 797151.

Așkar Ș, Yıldırım M. Broyler Damızlık ve Ticari Broyler Sürülerinde Tavuk Anemi Virüsünün ve Antikor Varlığının Araștııılması. Ankara Üniversitesi Veteriner Fakültesi Dergisi 2011; 58: 247-253.

Chu DK, Poon LL, Chiu SS, Chan KH, Ng EM, Bauer I, Cheung TK, Ng IH, Guan Y, Wang D, Peiris JS. Characterization of a novel gyrovirus in human stool and chicken meat. Journal of Virology 2012; 55(3): 209213.

Farkas T, Tanaka A, Kai K, Kanoe M. Cloning and sequencing of the genome of chicken anemia virus (CAV) TK-5803 strain and comparison with other CIAV strains. The Journal of Veterinary Medical Science 1996; 58 : 681-684. doi: 10.1292/jvms.58.681
Ganar K, Shah M, Kamdi BP, Kurkure NV, Kumar S. Molecular characterization of chicken anemia virus outbreaks in Nagpur province, India from 2012 to 2015. Microbial Pathogenesis 2017; 102: 113-119.

Hadimli HH, Erganiș O, Güler L, Uçan US. Investigation of Chicken Infectious Anemia Virus Infection by PCR and ELISA in Chicken Flocks. Turkish Journal of Veterinary and Animal Sciences 2008; 32(1):1-5

Hailemariam Z, Omar AR, Hair-Bejo M, Giap TC. Detection and characterization of chicken anemia virus from commercial broiler breeder chickens. Virology Journal 2008; 5:128.

ICTV (International Committe on Taxonomy of Virus) Access Address: https://talk.ictvonline.org/taxonomy/.asp, Date of access: 2018.

Kim HR, Kwon YK, Bae YC, Oem JK, Lee OS. Molecular characterization of chicken infectious anemia viruses detected from breeder and broiler chickens in South Korea. Poultry Science 2010; 89 (11): 2426-2431.

Krapez U, Barlic-Maganja D, Toplak I, Hostnik P, Rojs OZ. Biological and molecular characterization of chicken anemia virus isolates from Slovenia. Avian Diseases 2006; 50 (1): 69-76.

Li Y, Fang L, Cui S, Fu J, Li X, Zhang H, Cui Z, Chang S, Shi W, Zhao P. Genomeic Characterization of Recent Chicken Anemia Virus Isolates in China. Frontiers in Microbiology 2017; 8: 401.

Maggi F, Macera L, Focosi D, Vatteroni ML, Boggi U, Antonelli G, Eloit M, Pistello M. Human gyrovirus DNA in human blood. Emerging Infectious Diseases Journal 2012; 18(6): 956-959.

Noteborn MHM, De Boer GF, Van Roozelaar DJ., Karreman C, Kranenburg O, Vos JG, Jeurissen SHM, Hoeben RC, Zantema A, Koch G, Van Ormondt $H$, Van Der Eb AJ. Characterization of cloned chicken anemia virus DNA that contains all elements for the infectious replication cycle. Journal of Virology 1991; 65:3131-3139.

Phan TG, Li L, O'Ryan MG, Cortes H, Mamani N, Bonkoungou IJO, Wang C, Leutenegger CM, Delwart E. A third gyrovirus species in human faeces. Journal of General Virology 2012; 93: 1356-1361.

Renshaw RW, Soiné C, Weinkle T, O'Connell PH, Ohashi K, Watson S, Lucio $B$, Harrington S, Schat KA. A hypervariable region in VP1 of chicken infectious anemia virüs mediates rate of spread and cell tropism in tissue culture. Journal of Virology 1996; 70: 8872-8878.

Rosario K, Breitbart M, Harrach B. Revisiting the taxonomy of the family Circoviridae: establishment of the genus Cyclovirus and removal of the genus Gyrovirus. Archives of Virology 2017; 162(5):1447-1463. doi: 10.1007/s00705-017-3247-y

Schat KA. Circovirus infections, chicken infectious anemia. In: Saif YM, Barnes H J, Fadly AM, Glisson JR, McDougald LR, Swayne DE editors. Diseases of poultry. 11th ed, lowa State University Press Ames IA; 2003. p. $182-202$

Sauvage V, Cheval J, Foulongne V, Gouilh MA, Pariente K, Manuguerra JC, Richardson J, Dereure O, Lecuit M, Burguiere A, Caro V, Eloit M. Identification of the first human gyrovirus, a virus related to chicken anemia virus. Journal of Virology 2011; 85: 7948-7950.

Senthilkumar N. Molecular characterization of chicken infectious anemia virus and antineoplastic effect of its VP3 protein. [Dissertation]. Deemed University, IVRI, Izatnagar, India; 2004.

Zhang X, Xie Q, Ji J, Chang S, Liu J, Chen F, Ma J, Bee Y. Complete genome sequence analysis of a recent chicken anemia virus isolate and comparison with a chicken anemia virus isolate from human fecal samples in China. Journal of Virology 2012; 86: 10896-10897.

Zhang X, Liu Y, Wu B, Sun B, Chen F, Ji J, Xie Q. Phylogenetic and molecular characterization of chicken anemia virus in southern China from 2011 to 2012. Scientific Reports 2013; 3: 3519. http://doi.org/10.1038/ srep03519. 
Aşkar S

Yuasa N, Taniguchi T, and Yoshida I. Isolation and some characteristics of an agent inducing anemia in chicks. Avian Diseases 1979; 23:366-385.

Yamaguchi S, Imada T, Kaji N, Mase M, Tsukamoto K, Tanimura N, Yuasa $\mathrm{N}$. Identification of a genetic determinant of pathogenicity in chicken anaemia virus. Journal of General Virology 2001; 82: 1233-1238. 